\title{
A quantitative analysis of the quality and content of the health advice in popular Australian magazines
}

\author{
Amanda Wilson, ${ }^{1}$ David Smith, ${ }^{1}$ Roseanne Peel, ${ }^{1}$ Jane Robertson, ${ }^{2}$ Kypros Kypri ${ }^{1}$
}

\footnotetext{
T he media play a central role in the dissemination of information on health and medical issues. More people obtain information about new developments through the media than from health professionals in Australia and elsewhere. ${ }^{1,2}$ Media coverage of health news has been shown to influence how people perceive medical issues and to affect health behaviours in both positive and negative ways. ${ }^{3,4}$

Health advice has been provided by magazines for many decades and while publication sales in all areas of the media are falling, magazines remain a popular way to seek health information. ${ }^{5}$ Magazine proprietors widely promote their publications as having a substantial impact on readers. There is evidence that shows media coverage can affect health behaviour, such as the rise in the number of mammogram appointments after Kylie Minogue was diagnosed with breast cancer ${ }^{3}$. It is reasonable to assume that lifestyle magazines, especially those with the word 'health' in their title, would have an impact on health literacy and behaviour.

Lifestyle magazines target specific age and gender readerships and are very popular in Australia. The top six magazines in Australia have a combined annual circulation of over 1.7 million with a readership of nearly five times that figure (Table 1). Around $60 \%$ of Australians over 15 years of age read at least one magazine every week and in the year to June 2013, Australians spent $\$ 789$ million buying 150 million magazines. ${ }^{6,7}$

The impact of the media on health literacy along with evidence of poor quality health reporting presents a strong rationale for implementing measures to improve media coverage. ${ }^{2,8}$ Most Australian lifestyle
}

\begin{abstract}
Objective: To examine how health advice is provided in popular magazines and the quality of that advice.

Methods: A prospective quantitative analysis of the quality of health advice provided in Australian magazines between July and December 2011 was conducted. A rating instrument was adapted from the Media Doctor Australia rating tool used to assess quality of health news reporting. Criteria included: recommends seeing a doctor; advice based on reliable evidence; advice clear and easily applied; benefits presented meaningfully; potential harms mentioned; evidence of disease mongering; availability and cost of treatments; obvious advertising; vested interest, and anecdotal evidence.

Results: 163 health advice articles were rated showing a wide variation in the quality of advice presented between magazines. Magazines with 'health' in the title, rated most poorly with only $36 \%(26 / 73)$ of these articles presenting clear and meaningful advice and 52\% (38/73) giving advice based on reliable evidence.

Conclusions: Australian magazines, especially those with health in the title, generally presented poor quality, unreliable health advice. Teen magazine Dolly provided the highest quality advice.

Implications: Consumers need to be aware of this when making health choices.

Key words: life expectancy, efficiency, data envelopment analysis, Māori, New Zealand
\end{abstract}

magazines dedicate significant space to health advice including 'question and answer' sections, columns, stories, product promotion and short 'break-outs' on health information. Advice includes prevention and/or treatment, and is written by medical doctors, dietitians, herbalists, psychologists or lay journalists. There is strong evidence around the poor quality of health reporting in the media. ${ }^{8-10}$ However, while one study comparing health information presented in two magazines found less than optimal reporting, there has been no quantitative evaluation of the quality of this health advice. ${ }^{11}$

This study aimed to examine the way health advice is provided in popular magazines and assess the quality of that advice. This is an area of the health media with a substantial ongoing audience and the potential to negatively affect health behaviour. Our findings provide insight into the quality of this medium and an initial step towards raising this quality and awareness around it.

\section{Methods}

The study was a prospective quantitative analysis of the quality of health advice provided in Australian lifestyle magazines. Magazine articles specifically providing health advice, as opposed to health news or information, were collected from lifestyle magazines over the six months July to December 2011. Hard copies of each magazine were purchased at the time of publication (via subscriptions) and manually

\footnotetext{
1. School of Medicine and Public Health, University of Newcastle, New South Wales

2. Clinical Pharmacology, University of Newcastle, New South Wales

Correspondence to: Dr Amanda Wilson, University of Newcastle - Medicine and Health, University Drive, Callaghan, New South Wales 2308;

e-mail: Amanda.wilson@newcastle.edu.au

Submitted: March 2016; Revision requested: June 2016; Accepted: August 2016

The authors have stated they have no conflict of interest.
} 
searched-for articles. Articles were eligible for inclusion if they explicitly recommended interventions to treat, manage or prevent diseases or health issues and were not obviously advertisements. The articles included dedicated health advice columns, long articles on specific problems and short break-out articles on how to improve health or deal with health issues. Ten Australian magazines were included in the study (Table 1). The magazines were selected on the basis of their popularity (circulation rates) and target readership (gender, interest and age range). Every issue of each magazine published from 1 July to 31 December 2011 was included in the study.

The rating instrument used in this study was adapted from the Media Doctor Australia rating instrument used to assess the quality of health reporting in the Australian news media. ${ }^{12}$ The 10 criteria are shown in Box 1 . For each article, a search was conducted to locate any relevant journal articles, author qualifications or other supporting literature that might assist the reviewers in making their assessments of the quality of the information reported. A coding manual was developed to guide the assessments and interpretation of the criteria. For each article, the 10 criteria were assessed as 'satisfactory,' 'not satisfactory' or'not applicable.' Agreement was achieved between raters as to how the evaluation criteria would be interpreted. All differences between raters in the scores assigned for individual criteria were resolved by consensus during regular face-to-face meetings. Ethics approval was not sought given that the data are in the public domain.

A total of 163 articles providing health advice were collected over the six months by an experienced researcher (RP). Two of three experienced Media Doctor Australia raters (AW, DS, RP) independently assessed each article. A descriptive analysis was conducted and

\section{Box 1: Rating criteria.}

Articles were assessed for the extent to which they complied to the following 10 criteria:

1. Recommends seeing a doctor, if applicable

2. Advice is based on accepted medical practice or reliable evidence

3. Advice is clear and easily applied

4. Benefits of advice are presented in a meaningful way

5. Potential harms of recommended treatments are mentioned

6. There is no evidence of "disease mongering" (12)

7. The availability and costs of treatments are mentioned

8. The author has no apparent vested interests

9. There is obvious advertising

10. Anecdotal evidence is used appropriately

consensus scores calculated on each of the 10 rating criteria. The results are presented as the number and percentage of items within each magazine that were considered to be satisfactory for each criterion and across all criteria. Only one article was included from the magazine Girlfriend and while it rated satisfactory on all items, it has not been included in the overall results.

\section{Results}

The range of different health topics covered by the articles reviewed is presented in Table 2. The most frequently discussed topics related to gynaecological and urinary tract matters (22.6\%) and the use of vitamin and mineral supplements (14\%). Of the 984 criteria assessed from 163 articles, only 570 (58\%) were assessed 'satisfactory'. However, there was a wide range of quality between publications (see Table 3) with Dolly at 100\%, and Women's Health at $26 \%$.

The magazine Dolly scored well on all items. Most of the articles from Dolly took the form of reader questions with answers provided by a practising medical doctor. The topics covered were typically those important to adolescents, such as skin problems, body

\begin{tabular}{lcccc}
$\begin{array}{l}\text { Table 1: Magazine readership and target audience. } \\
\text { Title }\end{array}$ & $\begin{array}{l}\text { Circulation } \\
\text { Readership } \\
\text { Women's Weekly }\end{array}$ & $\begin{array}{c}\text { Target Audience } \\
\text { (\% of readership) }\end{array}$ & Frequency \\
\hline Woman's Day & 470,221 & $2,348,000(80)$ & Female 25-54 years (87) & Monthly \\
\hline New Idea & 365,266 & $1,802,000(84)$ & Female 25-54 years (85) & Weekly \\
\hline Cosmopolitan & 303,264 & $1,192,000(83)$ & Female all ages (NA) & Weekly \\
\hline Cleo & 125,548 & $529,000(85)$ & Female 18-34 years (63) & Monthly \\
\hline Women's Health & 105,157 & $378,000(89)$ & Female 18-30 years (59) & Monthly \\
\hline Dolly & 92,323 & $417,000(87)$ & Female 25-44 years (57) & Monthly \\
\hline Girlfriend & 90,318 & $318,000(91)$ & Female 14-17 years (47) & Monthly \\
\hline Men's Health & 80,014 & $318,000(89)$ & Female 14-17 years (51) & Monthly \\
\hline Good Health & 73,086 & $392,000(20)$ & Male 25-44 years (56) & Monthly \\
\hline
\end{tabular}

image and emerging sexuality, however, concerns including depression, severe anxiety and suicidal tendencies were also raised. From a clinical perspective of quality of content, the two most important rating criteria were advice is based on accepted medical practice or reliable evidence and benefits of advice are presented in a meaningful way. There were 160 articles where both of these criteria could be assessed (Table 4). These results demonstrate a wide variation in the quality of advice presented between magazines. Magazines with the word 'health' in the title, rated most poorly with only $36 \%$ (26/73) of these articles presenting advice that was clear and meaningful and $52 \%$ (38/73) of the articles presenting advice based on reliable evidence or reflected current practice.

\section{Conclusions}

The findings from this study show that overall, the quality of advice presented in magazines was low, although there was a wide variation between magazines. Magazines with the word 'health' in the title, such as Women's Health, presented the lowest quality advice, while the teen magazine Dolly rated as the highest quality.

The media shape the public's perceptions of both health and disease and influence health behaviour and use of health care interventions. ${ }^{1,2}$ The Press Council of Australia's Advisory Guidelines states: "The Press Council views with concern inadequately researched reports on health and medical matters appearing in the press and in the media as whole. The dangers of exciting unreasonable fears or hopes are far too great for anything but the most careful treatment".13 This study shows that popular

\begin{tabular}{|c|c|}
\hline Topic & $\begin{array}{l}\text { Number of } \\
\text { articles (\%) }\end{array}$ \\
\hline $\begin{array}{l}\text { Gynaecological and female urinary tract } \\
\text { disorders, sexually transmitted infections, } \\
\text { contraception/fertility/pregnancy }\end{array}$ & $37(23 \%)$ \\
\hline Vitamin and mineral supplements & $22(14 \%)$ \\
\hline Cardiovascular disease/blood pressure & $12(8 \%)$ \\
\hline Cancer & $12(8 \%)$ \\
\hline Brain/memory disorders & $7(4 \%)$ \\
\hline Gastrointestinal disorders & $7(4 \%)$ \\
\hline Respiratory disorders & $6(4 \%)$ \\
\hline Pain & $5(3 \%)$ \\
\hline Diabetes & $3(2 \%)$ \\
\hline All other topics & $52(31 \%)$ \\
\hline
\end{tabular}


Australian lifestyle magazines, especially those with the word health in their title, are not meeting these standards. The findings presented in this study only represent a relatively brief snapshot of a specific and diminishing section of the media landscape. However, magazine readers should be informed that the health advice provided by these magazines is often poorly presented and unreliable.

Specifically titled health magazines rated poorly on all measures. However, the magazines marketed to adolescent girls performed well overall. In Dolly, all reader questions were responded to in an accessible, non-judgmental manner with encouragement to seek help from appropriate health professionals. This magazine provided excellent examples of ethical ways to deliver health advice and also highlighted the need for this type of advice to be provided for this particular age group.

The overall range of health advice topics was very limited and did not include any important contemporary health issues such as smoking, obesity and immunization. The two most commonly discussed topics were genitourinary issues and the use of vitamins and minerals. While not presented in this paper, we collected data on advertisements in close proximity to the advice rated, and the most common advertisements were for female genitourinary products and vitamins and minerals, suggesting a possible financial conflict of interest. Advertising is by its nature, manipulative and strategic. ${ }^{14} \mathrm{~A}$ strong correlation between advertisement placement and article content is an effective marketing strategy that has been shown to exist even in medical journals. ${ }^{15}$

\section{Implications}

The findings from this study raise questions around the social responsibility of the media. Most journalists and public health providers believe that health is a special commodity that gives rise to particular social responsibilities. ${ }^{16,13}$ If the public has a right to know it also has a right to be provided with information that is accurate and complete ${ }^{17}$. Many studies have looked at the influence and quality of health news stories, but few, if any, have looked at the quality of health advice given in magazines. The findings present here are important because magazines are not generally subjected to the same rigours of news journalism and

\begin{tabular}{lccc} 
Table 3: Criteria assessed as satisfactory. & & & \\
Magazine & Articles & Criteria Assessed & Criteria assessed satisfactory \\
& $\mathbf{n}$ & $\mathbf{n}$ & $\mathbf{n}(\%)$ \\
\hline Good Health & 38 & 259 & $126(49)$ \\
\hline New Idea & 26 & 164 & $68(41)$ \\
\hline Women's Weekly & 19 & 116 & $78(67)$ \\
\hline Women's Health & 18 & 104 & $27(26)$ \\
\hline Men's Health & 17 & 102 & $70(69)$ \\
\hline Dolly & 16 & 84 & $84(100)$ \\
\hline Cosmopolitan & 13 & 85 & $69(81)$ \\
\hline Cleo & 9 & 46 & $32(70)$ \\
\hline Woman's Day & 3 & 20 & $12(60)$ \\
\hline
\end{tabular}

\begin{tabular}{lccc}
$\begin{array}{l}\text { Table 4: Number of articles assessed as satisfactory on two specific criteria. } \\
\text { Magazine }\end{array}$ & $\mathbf{n}$ & $\begin{array}{r}\text { Advice presented clearly and } \\
\text { meaningfully } \mathbf{n}(\%)\end{array}$ & $\begin{array}{r}\text { Advice based on reliable evidence } \\
\text { or medical opinion n (\%) }\end{array}$ \\
\hline Good Health & 38 & $21(55 \%)$ & $14(37 \%)$ \\
\hline New Idea & 26 & $12(46 \%)$ & $14(54 \%)$ \\
\hline Women's Weekly & 19 & $15(79 \%)$ & $14(74 \%)$ \\
\hline Women's Health & 18 & $4(22 \%)$ & $3(17 \%)$ \\
\hline Men's Health & 17 & $13(76 \%)$ & $9(53 \%)$ \\
\hline Dolly & 16 & $16(100 \%)$ & $16(100 \%)$ \\
\hline Cosmopolitan & 13 & $12(92 \%)$ & $7(77 \%)$ \\
\hline Cleo & 9 & $7(77 \%)$ & $1(33 \%)$ \\
\hline Woman's Day & 3 & $2(67 \%)$ & \\
\hline
\end{tabular}

the content is likely to be influenced by companies advertising 'health' products and interventions. This type of soft journalism appears in many different forms on the internet where health advice is presented as evidence based and current. We have shown that the quality of health advice provided in magazines is generally poor. This message is important in order to raise the awareness and promote critical thinking among health consumers.

\section{References}

1. Wilson AJ, Robertson J, Ewald BD, Henry D. What the public learns about screening and diagnostic tests through the media. Med J Aust. 2012;197(6):324-6.

2. Schwitzer G, Mudur G, Henry D, Wilson A, Goozner M, Simbra $M$, et al. What are the roles and responsibilities of the media in disseminating health information? PLOS Med. 2005;2(7):e215.

3. Kelaher M, Cawson J, Miller J, Kavanagh A, Dunt D, Studdert DM. Use of breast cancer screening and treatment services by Australian women aged 25-44 years following Kylie Minogue's breast cancer diagnosis. Int J Epidemiol. 2008;37(6):1326-32.

4. Li M, Chapman S, Agho K, Eastman CJ. Can even minimal news coverage influence consumer healthrelated behaviour? A case study of iodized salt sales, Australia. Health Educ Res. 2Jun;23(3):543-6.

5. Anstiss D, Lyons A. From men to the media and back again: Help-seeking in popular men's magazines. $J$ Health Psycogy. 2014;19(11):1358-70.
6. Australian Bureau of Statistics. 4172.0. - Arts and Culture in Australia: A Statitistical Overview. Canberra (AUST): ABS; 200.

7. Magazine Publishers of Australia. Magazine Markes Stabilises [Internet]. Sydney (AUST): MPA; 2015 [cited 2016 Jan 16]. Available from: http://magazines.org.au/ news/magazine-market-stabilis.

8. Wilson A, Bonevski B, Jones A, Henry D. Media reporting of health interventions: Signs of improvement, but major problems persist. PLoS One. 2009;4(3):e4831

9. Robinson A, Coutinho A, Bryden A, McKee M. Analysis of health stories in daily newspapers in the UK. Public Health. 2013;127(1):39-45.

10. Sumner $P$, Vivian-Griffiths $S$, Boivin J, Williams $A$, Venetis CA, Davies A, et al. The association between exaggeration in health related science news and academic press releases: Retrospective Observational Study. BMJ. 2014;349:g7015.

11. Brunner BP, Brunner Huber LR. 101 ways to improve health reporting: A comparison of the types and quality of health information in men's and women's magazines. Public Relat vew. 2010;36(1):84-6.

12. Smith DE, Wilson AJ, Henry DA. Monitoring the quality of medical news reporting: Early experience with media doctor. Med J Aust. 2005;183(4):190-3.

13. Moynihan R, Heath I, Henry D. Selling sickness: The pharmaceutical industry and disease mongering. $B M J$. 2002:324(7342):886-91.

14. Australian Press Council. Reporting Guidelines. Genera Press Release No.: 2401)Sydney (AUST):APC; 2001 April.

15. MacRury I. Advertisins. Oxon (UK): Routledge; 20.

16. Vlassov WV. Is content of medical journals related to advertisements? Case-control Study. Croat Med J. 2007;48(6):76-790.

17. Jordens $C F$, Lipworth $W L$, Kerridge $\mathrm{IH}$. The quality of Australian health journalism is important for public health. Med J Aust. 2013;199(7):448-9. 